
are written by the students themselves, with each profile sharing with the reader the individual's story of where they came from, what they are currently doing and where they see themselves headed in the future. This section also provides a great opportunity for space industry representatives to
identify some of the country's brightest students who may be at the forefront of leading the next Canadian innovation. programs, as well as many other learning opportunities, please visit the student section of the CSA website at: http://www.asc-csa.gc.ca/eng youth-students/17/
Jason Clement (B.A. Cultural Studies'98) currently works as a Communications Officer for the Space Learning Program at the Canadian Space Agency (CSA). Prior to joining the CSA in December 1999, Jason worked in the promotions department at what is now Virgin Radio and wrote his own section- called "Fresh Meet" - in a national magazine titled Fresh which profiled people in the 18-34 demographic from a variety of interesting fields. At the CSA Jron is responsible for the coordination of the Spare tions Program, the Student and Educator Professional Development Workshop Program, the Student/Youth section of the website as well as a variety of special projects including the the Student/Youth section of the website as well as a variety of special projects including the development of student programming for a number of space-related international conferences. Jason also represents Canada at the Working Group level of the International Space Education Board.

CROSSROADS

\title{
Medical Education for Exploration Class Missions \\ NASA Aerospace Medicine Elective at the Kennedy Space Centre
}

Gregory E. Stewart*, Laura Drud

\section{BACKGROUND}

For over a decade, the Canadian Space Agency (CSA) has selected Canadian medical Aerospace Medicine to attend NASA's prestigious Space Center (KSC) on the Space Coast in Florida or the Johnson Space Center (JSC) in Houston, Texas (1). Selected students have the privilege to learn from pioneers and leading experts in space life sciences about the physiologic adaptations that occur during space-flight as well as the preparations and medical support required for a Space Shuttle launch to the International Space Station (ISS).

\section{INTRODUCTION}

The spaceflight environment poses many challenges to astronauts. Understanding the effects of long duration space travel and how a crew medical officer (CMO) operates in this extreme environment was the focus of the research project. The knowledge and skills set for future CMOs as the endeavours to space exploration continue, and Canada's involvement in Cossed in this project.

Physicians are often chosen to be astronauls, however, non-physicians are often the during the two-year period leading up to the actual mission and there is no protocol for maintaining medical skills during a long duration mission $(2,3)$. Therefore procedural skilldecay will be animportant

"To whom correspondence should be addressed Dr. Gregory E. Stewart

Email: gregstewart89@hotmail issue worth considering for long duration space sissions, and effective countermeasures should e events. Also, extensive equipment and supplies for the medical interventions cannot be provide due to the severe weight and volume constraints of spaceflight $(4,5,6)$. Thus, risk management strategies dictate that only those situations that are the most severe, or the most easily diagn The greatest medical concerns to a crew on an exploration class mission include (i) radiation exposure (ii) human behaviour and performance and (iii) physiologic alterations in the reduced gravitational environment $(2,4,5)$. With the cancellation of the Constellation program, the current plan for NASA is to support the extension of the ISS through 2020. Thus, the ISS will serve as platform for space life sciences research as well as preparation for future exploration class missions by increasing our understanding of space physiology

The standard of care on the ISS is to support the crew $24 / 7$ from Mlssion Control and definitive medical care (2). For fuut to Earh for class missions, however, the medical care system will need to be very autonomous and self-sufficient due to the communication delay and extremely long separation from definitive medical care. Furthermore, procedural skill decay will become a mission-threatening medical consideration, the expected rate of a significant medical even extrapolated to a 25 year Mars mission involving 6 crew members is approximately 1 event/mission 
Current countermeasures for procedural skill decay include efficient and structured medical training design (9). Specifically, the educational experience can be enhanced by designing realistic simulations, also known as High-fidelity Environment Analog Training (HEAT) (10,11). Similar to fight simulators, medical simulation allows effective training and maintenance of skills, and has been successful in improving the training of physicians in safety critical environments including the Emergency Department, the Operating Room and the Intensive Care Unit $(12,13)$. NASA has also developed a flight-ready human patient simulator 135) and porate in simulated microgravity (i.e. KC$35)$ and potentially spaceflight $(14,15,16)$.

The importance of simulation based which is cribes efficient reasoning ace judgmel as distinguishing crew characteristics in safety critical environments (17). Essentially, the model coscribes two cognitive systems for problem solving: reasoning

System 2: characterized by deliberate, careful reasoning.

Thus, simulation based learning allows the student to develop essential reasoning and judgment skills (i.e. develop System 2) while continued practice allows unfamiliar situations to become more automated and efficient (i.e. develop System 1). This allows advancement to more complex tasks once competence in basic skills has

Ideally, efficient training design mitigates human error and the risk of an adverse event to a safe and acceptable level. In aviation, it is accepted that errors and mistakes by crewmembers will occur in any flight and a non-blame approach to error is emphasized (18). By shifting the focus other thre to safety, the entris is deal with as any is discussed in an open atmosphere to determine is discussed in an open almosphere to determine (19). This philosophy of error management has been formalized into simulation based training entitled Crew Resource Management It was developed in the late 1970 s when it was found that up to $70 \%$ of aviation accidents were due to crew issues including failure in communication, lack of situational awareness and poor error management (20). Similarly in medicine, communication issues have been implicated in $70 \%$ of perinatal deaths and injuries (21). Also, it was found that $30 \%$ of neonatal resuscitation steps are not performed or performed incorrectly. Certainly, check-lists can be a helpful memory aid in these safety critica environments, especially when all relevant human actors are not addressed (22).

Human factors engineering is the study of the interaction between humans and their working environment $(20,23)$. More specifically, its goal is to understand how human limitations, capabilities, characteristics, behaviours and responses will affect performance in a given environment. Furthermore, the application of our understanding of human factors to the design of an intuitive system wil minimize risk and optimize performance $(24,25)$. For example, telemedicine has been used in the design of a model for safe technology ontario Cana (26). The study used a preceptor guided training schedule to meet minimum case requirements. The preceptor allowed progression from direct "scrubbed-in" supervision to "verbalonly" supervision and finally to telementoring when competent skill and judgment was observed. The study demonstrated the feasibility of a training program for laparoscopic colon surgery that shortens hospital stays and ultimately improves patient outcomes.

Telemedicine can also be applied to space travel. A case in point is Just-In-Time telemedicine for ultrasound exam, as it provides a means to investigate a wide variety of conditions in remote \& austere environments (27). For the ISS, the training design uses a pre-mission familiarization with the equipment followed by on-board CD-ROM based skill enhancement, as well as remote expert guidance for patient exam. This telemedicine raining algorithm developed for spaceflight has also been used to rapidly train medical and nonmedical personnel to perform complex procedures (28). Funhermore, it has been used to confirm (HAPE) in moun cling (29).

\section{CANADA'S INVOLVEMENT IN THE FUTURE OF}

XPlon to future exploration class missions is to develop a remote medical training program for crew medical officers. This could be a niche sector for the Great White North as it offers a vast and largely uninhabited geographic area, harsh climate and established medical infrastructure necessary to support the training of future astronaut-physicians. Thus, as the International Space Station nears completion, it demonstrates how teamwork and collaboration foster the motivation and determination to overcome even the greatest of obstacles. Ultimately, efforts to better our world will undoubtedly inspire the next generation of scientists and explorers to improve their world as well. No matter how large or small the contribution, all those exploration effort can be proud of their motives.

\section{ACKNOWLEDGEMENTS}

Dr. Stewart could not have taken part in the Aerospace Medicine Elective without the dedication Space Cenker and the Canadian Space Agency who made this incredible experince possible.

\section{REFERENCES}

Canadian Space Agency. http://www.asc-csa.gc.ca/eng/ astronauts/osm training candidates as. Accessed February 22, 2010.

2. Needs and Capacity Study: Provision of Medical Care Solutions for Long Duration Human Space Flight Missions. NORTH Network. http://www.asc-csa.gc.ca/pdf/ CSEW2008_Medical_Care_Solutions.pdf. Accessed February 22, 2010

3. Ball JR, Evans $\mathrm{CH}$, eds. Committee on Creating a Vision for Space Medicine During Travel Beyond Earth Orbit, Board on Health Sciences Policy, Institute of Medicine. Safe Passage: astronaut care for exploration missions. Washington, DC: National Academy Press; 200

4. Fogleman G, Davis JR, Stegemoeller CM. Bioastronautics Roadmap: A risk reduction strategy for Human Space Exploration. Houston, TX: JSC. 2005

5. Baisden DL, Beven GE, Campbel MR, Charles JB, Dervay JP, Foster E, Gray GW, Hamilton DR, Holland DA, Jennings RT, Johnston SL, Jones JA, Kerwin JP, Locke J, Polk JD, Scarpa PJ, Sipes W, Stepanek J, Webb JT; Ad Hoc Com formance for long-duration spaceflight. Aviat Space Environ Med 2008. Jun, 79(6): 629-35.

6. Buckey JC. Space Physiology. New York, NY: Oxford University Press; 2006

NASA Fiscal Year 2011 Budget. http///www nasa gov/news budgetlindex.html Accessed February 222010

8. Billica RD, Simmons SC, Mathes KL, McKinley BA, Chuang CC, Wear ML, Hamm PB. Perception of medical risk of spaceflight. Aviat Space Environ Med. 1996. May, 67(5): 467-73.
Grantcharov TP, Reznick RK. Teaching Procedural Skills.

10. Wang EE, Quinones J, Fitch MT, Dooley-Hash S, GriswoldTheodorson S, Medzon R, Korley F, Laack T, Robinett A, Clay L. Developing Technical Expertise in Emergency The Role of Simulation in Procedural Skill Acquistion. Acad Emerg Med. 2008. Nov 15(11).

11. Gurusamy K, Aggarwal R, Palanivelu L, Davidson BR. Systematic review of randomized controlled trials on the effectiveness of virtual reality training for laparoscopics surgery. Brit Journ Surg. 2008. 95: 1088-1097

12. Lammers, RL. Learning and Retention Rates After Training in Posterior Epistaxis Management. Acad Emerg Med 2008. Nov 15(11).

3. Kovacs G, Bullock G, Ackroyd-Stolarz S, Cain E, Petrie D. A Randomized Controlled Trial on the Effect of Educational Interventions in Promoting Airway Management Skill Main-

14. Cambeil MR, Bill RD, Joho

fampbel MR, Blica RD, Johnston MicL, Muller MS. PerEnviron Med. 2002. Sept, 73(9): 907-911.

15. McFarlin $K$, Sargsyan $A E$, Meton $S$, Hamiton DR Dut chavsky SA. A surgon's guide to the universe. Surgery. 2006. May, 139(5): 587-590. Astronauts to Manage Trauma (Emergencies): Integrating Human Patient Simulation into Medical Operations for NASA. Trauma Care. 2006. Winter 16(1): 26-30.

17. Sinclair $D$, Croskerry P. Patient safety and diagnostic error. CFP. 2010. 56:28-30.

agement: lessons from aviation. BMJ. 2000. 320:781-5.

9. Amalberti R, Wioland L. Human error in aviation. In Soekha $\mathrm{H}$, ed. Aviation safety: human factors, system engineering, fight operations, economics, strategies, management. Brill Academic Publishers. 1997. pp 91-108.

20. Rathjen T, Whitmore M, McGuire K, Goel N, Dinges DF, Tvaryanas AP, Zehner G, Hudson J, Dismukes RK, Musson DM. An introduction to human factors in aerospace. In: Davis JR, Johnson R, Stepanek J, Fogarty JA, eds

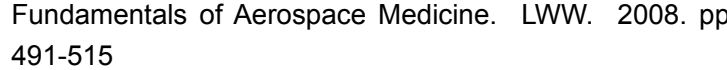

21. Thomas EJ, Taggart B, Crandell S, Lasky RE, Williams AL, Love LJ, Sexton JB, Tyson JE, Helmreich RL. Teaching reandomized trial Jo Nof

22. Hales BM, Pronovost PJ. The checklist - $a$ tool for erro management and perfom Care. 2006. 21: 231-235

23. Kubose TT, Patel VL, Jordan D. Dynamic adaptation to critical care medical environment: error recovery as cognitive activity. Proceedings of the 2002 Cognitive Science Society, 2002. pp 43. 
24. Patel LP, Cohen T. New Perspectives on error in critical care. Cur Opin Crit Care. 2008. 14:456-459

Stone R, McCloy R. Ergonomics in Medicine and Surgery. BMJ. 2004. 328:1115-8

26. Schlachta CM, Sorsdahl AK, Lefebvre KL, McCune ML, Jayaraman S. A model for longitudinal mentoring and telementoring of laparoscopic colon surgery. Surgical Endoscopy. 2009. 23:1634-1638.

27. Foale CM, Kaleri AY, Sargsyan AE, Hamilton DR, Melton S, Martin D, Dulchavsky SA. Diagnostic Instrumentation Aboard ISS: Just-In-Time Training for Non-Physician Crewmembers. Aviat Space Environ Med. 2005. June, 76(6):

Gregory E Stewart (BMSc MD CCFP(c)) completed medical school at The University of Ottawa and is now a resident at The University of Western Ontario in the Rural Family Medicine Program in Goderich. As a pilot and traveler as well as a physician in training, he investigated "Medical Education for Exploration Class Missions" because he was interested in learning about the medical concerns of long duration space travel and how a CMO operates in this extreme environment.

Laura Drudi (M.D., C.M. candidate 2013) is a third year medical student at McGill University. Her interest in combining her two passions of space and medicine has led her to conduct aerospace medicine research. She will be taking a one year's leave of absence from the Faculty of Medicine and will be pursuing a Diploma of Space Studies and an MSc in Experimental Surgery prior to completing her MD. She hopes to work for the manned space program as a flight surgeon and to further continue her research in space life sciences.

CROSSROADS

\title{
Ultrasound: From Earth to Space
}

\author{
Jennifer Law*, Paul. B. Macbeth
}

\begin{abstract}
Ultrasonography is a versatile imaging modality that offers many advantages over radiography, computed tomography, and magnetic resonance imagvantages over radiography, computed tomography, and magnetic resonance inagcine including diagnosis of medical and surgical diseases, management of obstetric and gynecologic conditions, assessment of critically ill patients, and procedura guidance. Advances in telecommunications have enabled remotely-guided ultraso-
nography for both geographically isolated populations and astronauts aboard the International Space Station. While ultrasound has traditionally been used in spaceflight to study anatomical and physiological adaptations to microgravity and evaluate countermeasures, recent years have seen a growth of applications adapted from terrestrial techniques. Terrestrial, remote, and space applications for ultrasound are reviewed in this pape
\end{abstract}

Keywords: Ultrasound, Spaceflight, Telemedicine, Telesonography, Remote consultation

INTRODUCTION

The use of ultrasound to diagnose and facilitate therapeutic interventions has become routine in many areas of medicine and surgery (1). With advances in computing power and probe design, ultrasound systems have become a widely available imaging modality. Traditionally, ultrasound is best known for its assessment of pregnancy and fetal growth. A growing number of applications have developed to include detailed assessments of almost every organ system. Clinicians have also identified benefits in trauma, critical care, and remote diagnostics. Ultrasound is an ideal diagnostic tool as it is noninvasive, low-cost, and highly portable. Image gependent As a result ultrasound has traditionally been limited to expert users. With new advances in ultrasound technology and personnel training the use of ultrasound has expanded beyond these traditional boundaries and has become an extension of the physical examination to many Bedside ultrasound assessments have enhanced physicians' capabilities ${ }^{*}$ To whom correspondence should be addressed

${ }^{*}$ To whom correspon University of Texas Medical Branch Division of Aerospace Medicine to accurately diagnose and understand patient physiology with the benefit of real-time feedback (2). this review we discuss the development of ultrasound technology and its expanded assessment of patients. A detailed description of its applications will be highlighted with discussion of its remote capabilities and utility for human space exploration.

\section{BACKGROUND}

History of ultrasound. The origins of ultrasonography can be traced back as far as the early 1800s, when Swiss physicist Jean-Daniel Colladon accurately determined the speed of sound through ware. In the late 1800s, Pine Curie and Jacques and pressure in crystiline materias now known as the presele in ceffect. This breakthrough low to the creation of the modern ultrasound transducer. It was not until the late 1930s when Austrian psychiatrist Dr. Karl Dussik demonstrated the clinical utility of ultrasound by generating images of brain tumors. A decade later, Dr. George Luwig characterized the differences of sound waves in different tissues. Early clinical applications primarily focused on clinical assessment of pregnancy and fetal development. As the technology matured, more clinical applications 